\title{
When do social cues and scientific information affect stated preferences? Insights from an experiment on air pollution
}

\author{
Dominique Ami ${ }^{\mathrm{a}}$, Frédéric Aprahamian ${ }^{\mathrm{b}}$, Olivier Chanel ${ }^{\mathrm{c}, *}$, Stéphane Luchini ${ }^{\mathrm{c}}$ \\ ${ }^{a}$ Aix-Marseille Univ., CNRS, EHESS, Centrale Marseille, AMSE, 5 Boulevard Maurice Bourdet CS50498, 13205, Marseille Cedex 01, France \\ ${ }^{\mathrm{b}}$ Université de Toulon and Aix-Marseille School of Economics (AMSE), 5 Boulevard Maurice Bourdet CS50498, 13205, Marseille Cedex 01, France \\ ${ }^{\mathrm{c}}$ Aix-Marseille Univ., CNRS, EHESS, Centrale Marseille, AMSE and IDEP, 5 Boulevard Maurice Bourdet CS50498, 13205, Marseille Cedex 01, France
}

\begin{abstract}
A B S T R A C T
Stated preference surveys are usually carried out in one session, without any follow-up inter-view after respondents have had the opportunity to experience the public goods or policies they were asked to value. Consequently, a stated preference survey needs to be designed so as to provide respondents with all the relevant information, and to help them process this in-formation so they can perform the valuation exercise properly. In this paper, we study ex-perimentally an elicitation procedure in which respondents are provided with a sequence of different types of information (social cues and objective information) that allows them to se-quentially revise their willingness-to-pay (WTP) values. Our experiment was carried out in large groups using an electronic voting system which allows us to construct social cues in real time. To analyse the data, we developed an anchoring-type structural model that allows us to estimate the direct effect (at the current round) and the indirect effect (on subsequent rounds) of information. Our results shed new light on the interacted effect of social cues and objective information: social cues have little or no direct effect on WTP values but they have a strong indirect effect on how respondents process scientific information. Social cues have the most noticeable effect on respondents who initially report a WTP below the group average but only after receiving additional objective information about the valuation task. We suggest that the construction and the provision of social cues should be added to the list of tools and controls for stated preference methods.
\end{abstract}

"Faced with the choice between changing one's mind and proving that there is no need to do so, almost everyone gets busy on the proof."

Galbraith, 1971.

\section{Introduction}

A commonly-held view is that respondents in stated preference surveys may have to discover their preferences, or even, to

\footnotetext{
* Corresponding author. AMSE, 5 boulevard Maurice Bourdet CS50498, 13205, Marseille c edex 01, France.

E-mail addresses: dominique.ami@univ-amu.fr (D. Ami), frederic.aprahamian@univ-amu.fr (F. Aprahamian), olivier.chanel@univ-amu.fr (O. Chanel), stephane.luchini@univ-amu.fr (S. Luchini).
} 
construct them during the interview (Carlsson, 2010). ${ }^{1}$ In these surveys, respondents have to form value judgments on public goods or policies they are often not familiar with and on which they are very likely not to have clear preferences. This does not apply only to non-market goods: there are many private market goods on which consumers can be uncertain regarding their preferences. When choosing these "experience goods" in markets, for instance movies, cars, wines, consumers have been shown to use non-price extrinsic cues such as expert opinions or others' preferences to make their decision (see, e.g., Aqueveque, 2006, 2008; Salazar and Oerlemans, 2016). However, the main difference from stated preference surveys is that consumers in markets can process information and learn their preferences over several consumption events. This is usually not the case in stated preference surveys. Surveys are carried out in one session, without any follow-up interview after respondents have had the opportunity to experience the public goods or policies they were asked to value. Consequently, a stated preference survey needs to be designed so as to provide respondents with all the relevant information, and to help them process this information so they can perform the valuation task properly. Our paper pursues this line of thought, exploring an elicitation procedure where respondents are provided with a sequence of different types of information. This procedure allows them to sequentially revise their willingness-to-pay (WTP) values.

Information provision has been studied extensively in the literature (see, e.g., Rowe et al., 1980; Bergstrom et al., 1990; Ajzen, 1996; Munro and Hanley, 1995; Spash, 2002; Maruyama and Kikuchi, 2004; Chanel et al., 2011). Often the underlying idea is that some information may be relevant for benefits assessment - usually referred to as objective information - whereas other types of information may lead to biased responses, for instance through a form of anchoring. Respondents may take their cues from the behavior of others in their social networks (real and virtual), which influences their value formation for the goods featured in contingent valuation (CV) studies (Polomé, 2003; List and Taylor, 2006). Respondents simply set their WTP values according to others' WTP, i.e. conform to a social norm, because they have difficulty processing the value of the proposed good or policy. Lohse et al. (2017) test this idea in a within-sessions design with real payments and show that mean payments in previous sessions have a significant impact on WTP values for $\mathrm{CO} 2$ reduction. ${ }^{2}$ Taking insights from these two strands of the literature, we hypothesize that the two types of information, social cues and objective information, interact with each other and have to be considered jointly.

To explore this, we carry out a CV experiment on long-term exposure to air pollution with large respondent groups. 60 to 100 people are surveyed simultaneously in the same room using an electronic voting system. Our elicitation procedure is as follows. First, we ask the respondents their WTP for the good based solely on their prior knowledge/information. We then construct social cues in real time in a controlled experimental setting by computing WTP statistics from the group's elicited WTP values and immediately showing them to all the respondents. The respondents are subsequently given the opportunity to revise their WTP. Next, we provide objective information (in our case, scientific information about the good) and allow respondents to further revise their WTP. We again assess the effect on the group's elicited WTP values and construct social cues by showing the result to the respondents, who can revise their WTP if they wish to do so (Chanel et al., 2006, 2007). ${ }^{3}$ In addition, we complement our baseline treatment described above by two additional between-respondent treatments. The first consists of adding a cheap talk script to the baseline treatment. Cheap talk, first proposed by Cummings and Taylor (1999), is a method of reducing hypothetical bias. Respondents are warned prior to the elicitation question about the dangers inherent in building their counterfactuals concerning what they would pay for the good with respect to what they would pay if it were provided for real. Dozens of published CV studies have tested whether the cheap talk approach really mitigates the hypothetical bias, with mixed results (Little and Berrens, 2004; Murphy et al., 2005; Stefani et al., 2014). Our cheap talk treatment uses a "neutral" script that not only points out that hypothetical surveys tend to elicit higher than real-life WTP, but also warns respondents that protest responses can produce lower and zero values. This added script is the only difference from the baseline experiment, thereby allowing us to study the interaction of cheap talk with information provision.

Our second additional between-respondent treatment is based on a behavioral approach borrowed from social psychology. Otherwise identical to the baseline treatment, it adds a commitment device in the form of signing a petition about environmental preservation (Ami et al., 2014). Social psychology has extensively studied how people can be induced to commit to target behavior by being asked to perform preliminary, usually costless, actions (Kiesler, 1971). Commitment appears to be stronger when obtained through a free decision, publicly made and signed (Joulé and Beauvois, 1998; - see also Jacquemet et al., 2011; for a discussion of commitment in stated preference surveys). In our petition treatment, we commit people to environmental preservation by asking them to sign a real petition (sent to the then candidates in the French presidential election) prior to participating in the CV experiment. They are free to sign or not, and do so in front of other people. The aim of this prior political behavior is to put people in a citizen framework, acting from the perspective of a person who is not purely self-interested. We then study how these experimentally generated citizens respond to scientific information and social cues.

\footnotetext{
${ }^{\mathbf{1}}$ The literature has long been divided on the fact that respondents in stated preference surveys are forming their preference during the valuation exercise. (Some) economists have been reluctant to accept this line of argument, which is supported more by psychologists (see, e.g., Fischhoff, 2005). Economists' reluctance to go too far down the psychology route, and their sticking to the ex-ante preference perspective, is understandable: without stable preferences, any assessment of social welfare is difficult, if not impossible, to make. This is problematic, since valuing public goods using surveys is the primary objective of stated preference methods (Mitchell and Carson, 1989). Recent developments in behavioral economics and interest in policy analysis, however, open new perspectives (Shogren and Thunström, 2016; Chetty, 2015; Fleurbaey and Schokkaert, 2013; Robinson and Hammitt, 2011).

${ }^{2}$ See also Alvarez-Farizo et al. (2007) in a valuation workshop setting.

${ }^{3}$ Our aim in this research was not to uncover the effect of "information" (whether it could be social cues or objective information) but rather on how to design a WTP elicitation procedure that would help respondents constructing their preferences towards an unfamiliar good. We were more interested in the combined effect of different types of information than the marginal effect of the different types of information taken separately (which has been already explored). Consequently, we did not consider sessions in which each type of information was dealt with separately.
} 


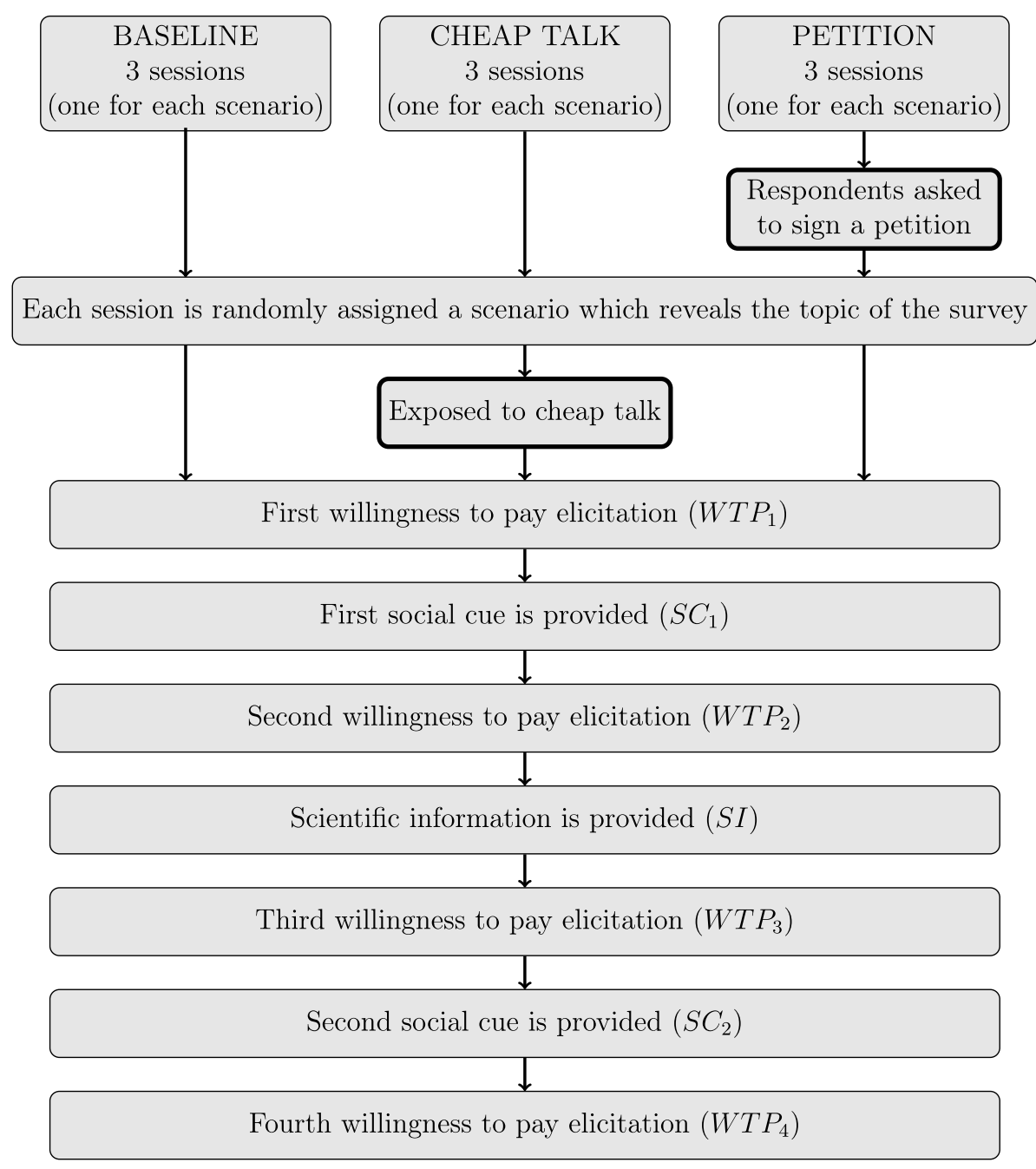

Fig. 1. Overview of the experimental design.

We analyse our data using descriptive statistics and by means of more structural econometric anchoring-type models. We find that social cues have only a marginal direct effect on WTP values but a large indirect effect on how respondents in our experiment process objective scientific information. We show that only respondents whose WTP falls below the mean WTP used as the first social cue respond to scientific information, even though they were initially non-sensitive to this social cue. Our take-home message is that social cues should be incorporated in the tools and controls of stated preference methods.

\section{Experimental design}

The impact of different types of information on WTP is studied in three experimental treatments (baseline, cheap talk, and petition) and three different scenarios (move, drug and regulation): this is a $3 \times 3$ design, and each of the 9 sessions uses the same sequential elicitation procedure throughout. Fig. 1 presents a summary of the experimental design.

Subjects were recruited in October 2006 in Marseille (2nd largest French city) through advertisements in local newspapers and on local TV news and randomly assigned to one of the nine sessions. ${ }^{4}$

Each respondent thus experienced only one treatment (baseline, cheap talk or petition) and one hypothetical scenario (either the drug, the move or the regulation hypothetical scenario). Each scenario was interacted with each treatment, hence 9 combinations. Each respondent was paid 20 euros (about 26 USD at the time of the survey) in gift vouchers. The experiment was conducted in the Provence-Alpes-Côte d'Azur Regional Council chamber. The voting room was equipped with an electronic voting system that allowed some of the information to be collected in real time from up to 120 respondents, thus ensuring that experiments were carried out in

\footnotetext{
${ }^{4}$ See appendix A for summary statistics on respondents' characteristics. Equality tests show that randomization was successful for almost all sociodemographics considered.
} 
the same manner in each session. We present, in the following, the scenarios, the elicitation procedure and the three treatments. ${ }^{5}$

\subsection{Hypothetical scenarios}

The good being valued in our experiment is a decrease in air-pollution-related effects. Obviously there is more than one way to elicit trade-off between a change in income and a change in air pollution exposure. As a form of robustness check, three typical scenarios were selected from the CV literature on air pollution, to ensure that our findings would not be scenario-specific. Participants were assigned to one session only and each session was devoted to one scenario only. Each participant was thus presented with only one scenario, which reveals the topic of the survey. The first scenario concerns a new drug (see Appendix B) that prevents adverse health effects of air pollution exposure for the respondent alone (Alberini et al., 2004; Krupnick et al., 2002). The second scenario involves moving the whole household (see Appendix C) to an already less polluted city (Viscusi et al., 1988; Guria et al., 2005; Aprahamian et al., 2007). The third scenario is about new regulations (see Appendix D) on air pollution that will increase market prices (Desaigues et al., 2007).

These scenarios involve different degrees of environmental conservation. The drug scenario does not refer to any particular measure to protect the environment, whereas the two other scenarios do. The move scenario implies that local action has already been taken, with the result that one of the locations has less air pollution. The regulation scenario presupposes national, or even international, measures to protect the environment. The scenarios also differ in the societal perspective adopted. The drug scenario refers to subjects' private sphere in a market-like situation, where only the subject benefits from the drug. The move scenario also refers to the private sphere of the respondents but concerns the entire household. Finally, the regulation scenario, which comes closer to current air pollution policies, concerns society as the whole. Overall, respondents in the drug scenario are asked to adopt a personal or consumer perspective, whereas in the regulation scenario they are asked to adopt a societal perspective, and the move scenario lies between the other two.

\subsection{Sequential elicitation procedure}

The CV experiment began with a self-administered survey on the respondent's socio-economic background and knowledge of air pollution. Once the self-administered survey was filled in, the elicitation procedure started. Each step of the procedure was simultaneously performed by all the respondents, using individual screens. The first round started with a list of closed-ended questions with ascending bid amounts; respondents used the electronic system to vote until they cast a 'no' vote. Thereafter, they reported their WTP in response to an open-ended question, to allow for more precise WTP values and/or very large amounts (round 1). The first elicited WTP value is thus solely based on the respondent's prior level of knowledge and experience of air-pollution-related effects. The mean WTP of all respondents was immediately computed and presented to the room (social cue 1). Thereafter, the respondents were given the opportunity to revise their WTP in response to an open-ended question (round 2). The next round involved presenting scientific and quantitative information on the effects of pollution (scientific information, see Appendix E). Information was simultaneously presented on individual screens and aloud, to ensure that all respondents had the same information. Respondents again had an opportunity to revise their WTP via the closed-ended ascending bid electronic voting mechanism, followed by an open-ended question (round 3). The mean was computed as before and presented to the room (social cue 2), and WTP was elicited once more with an open-ended question (round 4). A total of 4 WTP values were obtained for each respondent. To summarize, in each of the 9 sessions, every respondent answered 4 rounds of WTP questions and received various levels of social cues and scientific information:

- Round 1: no scientific information, no social cues,

- Round 2: information on social cues from Round 1 (SC1),

- Round 3: scientific information (SI) and information on social cues from Round 1 (SC1),

- Round 4: information on social cues from Round $3(S C 2)$, scientific information $(S I)$ and information on social cues from Round 1 (SC1).

Instructions were given to respondent one round at a time and respondents were not aware of the number of rounds to avoid end-game effects (on end-game effects, see, e.g., Andreoni, 1988). Communication between respondents - which might lead to private social cues from neighbors in the same session - was prevented in the following ways. Members of the research team were always present in the voting room. Sufficient space between seats, both between rows and within rows, made it impossible to read other respondents' open-ended WTP responses. For the ascending bid voting, each respondent had an individual voting system that did not display the vote outcome.

\subsection{The three experimental treatments}

\subsubsection{Baseline treatment}

We conducted 3 sessions in the baseline treatment. In each session, one of the three scenarios was randomly selected without

\footnotetext{
${ }^{5}$ Our experiment was an official collaboration between academics from the local University, the National Center for Scientific Research (CNRS) and the Regional council. The room we used was the room where elected members of the Council take decisions for the Region. One can hypothesize that respondents in our experiment thought that their opinion matters, which would indicate that their WTP values are consequential (Vossler et al., 2012). Open comments at the end of the questionnaire as well as short debriefing interviews with respondents selected at random or who spontaneously gave feedback, confirmed that respondents took the exercise seriously. Most stated that they were pleased to be asked about their opinions and preferences.
} 
Table 1

Percentages of WTP revisions by round, treatment and scenario.

\begin{tabular}{|c|c|c|c|c|c|c|}
\hline & \multicolumn{2}{|c|}{ Round $1 \rightarrow 2$} & \multicolumn{2}{|c|}{ Round $2 \rightarrow 3$} & \multicolumn{2}{|c|}{ Round $3 \rightarrow 4$} \\
\hline & \multicolumn{2}{|c|}{ Social cues 1} & \multicolumn{2}{|c|}{ Scientific information } & \multicolumn{2}{|c|}{ Social cues 2} \\
\hline & Increase & Decrease & Increase & Decrease & Increase & Decrease \\
\hline Whole sample $(\mathrm{N}=564)$ & 7.8 & 3.0 & 30 & 6.0 & 3.2 & 2.7 \\
\hline \multicolumn{7}{|l|}{ Baseline treatment } \\
\hline Whole sample $(\mathrm{N}=185)$ & 4.9 & 3.2 & 25.9 & 7.0 & 1.1 & 2.7 \\
\hline Drug $(N=41)$ & 2.4 & 4.9 & 12.2 & 4.9 & 2.4 & 4.9 \\
\hline Move $(\mathrm{N}=83)$ & 7.2 & 2.4 & 30.1 & 8.4 & 1.2 & 2.4 \\
\hline Regulation $(\mathrm{N}=61)$ & 3.3 & 3.3 & 29.5 & 6.6 & 0.0 & 1.6 \\
\hline \multicolumn{7}{|l|}{ Cheap Talk treatment } \\
\hline Whole sample $(\mathrm{N}=157)$ & 8.9 & 3.2 & 35.7 & 5.7 & 2.5 & 3.2 \\
\hline Drug $(\mathrm{N}=55)$ & 7.3 & 3.6 & 43.6 & 7.3 & 3.6 & 5.5 \\
\hline Move $(\mathrm{N}=42)$ & 11.9 & 0.0 & 50.0 & 2.4 & 2.4 & 0.0 \\
\hline Regulation $(N=60)$ & 8.3 & 5.0 & 18.3 & 6.7 & 3.3 & 1.7 \\
\hline \multicolumn{7}{|l|}{ Petition treatment } \\
\hline Whole sample $(\mathrm{N}=222)$ & 9.5 & 2.7 & 29.3 & 5.4 & 5.4 & 2.3 \\
\hline Drug $(\mathrm{N}=97)$ & 3.1 & 3.1 & 26.8 & 8.2 & 4.1 & 3.1 \\
\hline Move $(\mathrm{N}=63)$ & 14.3 & 3.2 & 36.5 & 1.6 & 3.2 & 3.2 \\
\hline Regulation $(\mathrm{N}=62)$ & 14.5 & 1.6 & 25.8 & 4.8 & 9.7 & 0.0 \\
\hline
\end{tabular}

replacement at the beginning of the experiment (each session thus had a different scenario) and presented to respondents, then WTPs regarding air pollution were elicited using the sequential procedure described above. The total number of subjects in the baseline treatment is 198 .

\subsubsection{Cheap talk treatment}

There were three sessions, identical to the baseline except for a neutral and light cheap talk script (see Appendix F for the script) that was read aloud and presented to the respondents both on the main screen of the voting room and on the individual screens just after the scenario was presented. The script is neutral in that it provides no quantitative information on the direction and the size of the hypothetical bias; it simply tells subjects that, in a hypothetical situation, respondents tend to over- or under-state their WTP as well as giving protest answers (see Ami et al., 2011; for more details). The aim of this treatment was to make respondents more aware of how others behave in similar hypothetical situations. All other aspects of the experiment were as in the baseline treatment. As in the baseline, each session in the cheap talk treatment was associated with a different hypothetical scenario. In total, 174 subjects participated to the cheap talk treatment.

\subsubsection{Petition treatment}

The sessions in the petition treatment are identical to the baseline except for a petition offered to each respondent before the valuation exercise. Three students from the Department of Psychology, who presented themselves as apolitical students, asked the subjects to sign the petition before entering the voting room. The students memorized and used the same script each time they presented the petition (see Appendix G for a full translation). All respondents in these sessions were exposed to the petition, which they were free to sign or not $(82.3 \%$ did). Herein, we adopt an intention to treat strategy: all respondents assigned to the petition treatment are included in the statistical analysis. This ensures that there is no selection bias in the data. The petition treatment therefore tests the effect of being exposed to political behavior on elicited WTP values (see Ami et al., 2014; for more details). All other aspects of the experiment were as in the baseline treatment. We carried out three sessions, each with a different hypothetical scenario. In total, 243 subjects participated to the petition treatment.

\section{Unconditional analyses}

\subsection{Sensitivity of WTP to information provision}

Table 1 presents the proportion of participants who are sensitive to social cues and scientific information, by scenario and experimental treatment. ${ }^{6}$ Namely, we report the percentage of participants who change their WTP (upwards and downwards) after

\footnotetext{
${ }^{6}$ In the following, we remove protest responses from the analysis. Responses were qualified as protest when they correspond to respondents expressing null WTP and giving a reason in closed-ended debriefing questions or open comments that can be described as protests. One reason was common to the three scenarios ("I am not the one who should pay to reduce my risk of falling victim to pollution") and one specific to the drug scenario ("I am against drugs"). Examples of open comments leading to protests and based on reasons not included in the closed-ended debriefing are: "I do not agree with the principle of paying", "I would not pay since I will only move to live in the country", or "I do not want to pay because the factories are the major polluters". We observed $6.5 \%$ of protest answers in the baseline treatment, $9.8 \%$ in the cheap talk treatment and $8.6 \%$ in the petition treatment.
} 
Table 2

Distance to the mean (in \%) and decision to revise by round and treatment.

\begin{tabular}{|c|c|c|c|c|c|c|c|c|}
\hline \multicolumn{3}{|c|}{ Round $1 \rightarrow 2$ (Social cues 1 ) } & \multicolumn{3}{|c|}{ Round $2 \rightarrow 3$ (Scientific information) } & \multicolumn{3}{|c|}{ Round $3 \rightarrow 4$ (Social cues 2 ) } \\
\hline \multicolumn{9}{|c|}{ Baseline treatment } \\
\hline Down & Equal & Up & Down & Equal & Up & Down & Equal & Up \\
\hline 52.5 & -3.8 & -60.2 & 4.7 & 3.1 & -29.4 & 99.4 & -9.9 & -95.8 \\
\hline \multicolumn{9}{|c|}{ Cheap talk treatment } \\
\hline Down & Equal & Up & Down & Equal & Up & Down & Equal & Up \\
\hline 308.1 & -14.6 & -58.9 & -24.7 & -6.9 & -20.3 & 111.4 & -25.3 & -51.8 \\
\hline \multicolumn{9}{|c|}{ Petition treatment } \\
\hline Down & Equal & Up & Down & Equal & Up & Down & Equal & Up \\
\hline 27.5 & -8.0 & -56.3 & 92.7 & -6.6 & -30.1 & 64.6 & -18.8 & -60.9 \\
\hline
\end{tabular}

each step in the sequence of information provision: social cue 1, scientific information, social cue 2.

First, there is a moderate effect of the first social cue, when participants are only relying on their prior knowledge of air pollution. Overall, only $10.8 \%$ of participants change their WTP after having been informed about the mean WTP of the participants in the session. This translates more into an increase than a decrease in WTP. We also observe that when respondents revise after the first social cue, the revision is more likely to be upwards than downwards, for almost all combinations of scenario and experimental treatment considered.

Second, overall, scientific information provision leads $36 \%$ to revise their WTP values. Participants in the baseline drug scenario are the least sensitive (17.1\%), whereas those in the move scenario combined with cheap talk are the most sensitive (52.4\%). The change in WTP values emerges clearly as more likely to be upwards: over the whole sample, $30 \%$ of participants revise upwards and $6 \%$ revise downwards, for all combinations of treatment and hypothetical scenario considered.

Third, information received in the third round regarding the mean WTP of the participants has the least effect on WTP values. Only 5.9\% of participants revise their WTP in the third round. This result holds for all combinations of scenario and experimental treatment considered, although some combinations seem to generate more sensitivity to the second social cue, e.g. the drug scenario combined with cheap talk (9.1\%) and the regulation scenario combined with the petition (9.7\%). There is no clear pattern of upwards and downwards revision by scenario and treatment: proportions are low in both directions.

Fourth, turning to the individual level, two main patterns emerge from the joint distribution of WTP revisions. First, a majority of participants (56.6\%) never change their mind throughout the experiment, i.e. they state the same WTP value in all four steps. Second, a sizeable number of participants $(25.3 \%)$ increase their WTP value only once, when scientific information is provided. The data reveals two further patterns of revision, but which concern much smaller groups of participants (4.4\% each): participants who only decrease their WTP value on receiving scientific information and participants who only increase their WTP on receiving the first social cue. When we split the sample by treatment, we again find the same four patterns. The most visible difference between treatments is that respondents who are insensitive to any kind of information provision are more numerous in the baseline treatment $(61.1 \%)$ and the petition treatment $(57.2 \%)$ than in the cheap talk treatment $(50.3 \%, \mathrm{p}=.029$ and $\mathrm{p}=.111$ respectively) Consequently, the share of respondents who revise their WTP upwards when scientific information is provided is greater in the cheap talk treatment $(31.2 \%)$ than in the baseline $(23.2 \%, \mathrm{p}=.063)$ or the petition $(23.0 \%, \mathrm{p}=.047)$ treatments.

Fifth, further examination indicates that, when revising, participants are most likely to reduce the gap between their WTP and the mean WTP from the session. For instance, 95.4\% of those increasing had a lower WTP than the mean session WTP in round 1, and $70.5 \%$ of those decreasing had a higher WTP than the mean. We therefore examine whether people whose WTP differs greatly from the mean are more likely to revise their WTP value. We first calculate the normalized distance between respondent's WTP and the mean WTP for $t=1,2,3$ :

$$
d_{i, t}=\left(W T P_{i, t}-\overline{W T P_{i, t}}\right) / \overline{W T P_{i, t}} \times 100
$$

where $W T P_{i, t}$ is the WTP for individual $i$ at round $t$ and $\overline{W T P_{i, t}}$ the associate sample mean. The normalization allows the distance to be expressed as percentages for comparison across treatments. In Table 2, we compute the mean of $d_{i, t}$ for three groups of participants: those who decrease their WTP, those who do not change their WTP and those who increase their WTP.

Results are intuitive, although on a small group of participants: displaying the mean WTP is more likely to influence participants with substantially higher WTP, who then revise downwards, and participants with substantially lower WTP, who then revise upwards. Participants who do not revise have WTPs closer to the mean WTP displayed in round 2. This result holds whatever the treatment considered. This relationship between the distance of WTP values to the mean WTP of the room and the decision to revise downwards or upwards also holds for social cues 2. In Table 2, we observe that the respondents who revise upwards after the second social cue are more likely to be below the mean in round 3 and those who revise downwards above it.

Table 2 also contains the same statistics computed using participants' WTP values elicited in round 3 and the undisplayed mean of the elicited WTP in round 2. We observe that participants who increase their WTP when scientific information is provided are more likely to have WTP values lower than the mean. Those who do not change have values closer to the mean, perhaps because they consider they should keep their WTP unchanged after observing that they were close to the mean WTP in the previous round. This is true in all treatments. It can be seen that, while most respondents who changed their bids did so between rounds 2 and 3 , those who changed their bids after receiving scientific information were on average closer to the mean than those who revised their scores based 


\begin{tabular}{|c|c|c|c|c|}
\hline & Round 1 & Round 2 (Social cues 1 ) & Round 3 (Scient. info.) & Round 4 (Social cues 2) \\
\hline Whole sample $(N=564)$ & 40.5 & 40.8 & $44.2^{* * * *}$ & 43.7 \\
\hline Standard Deviation & 66.9 & 66.3 & 68.0 & 67.3 \\
\hline \multicolumn{5}{|l|}{ By experimental treatment } \\
\hline Baseline $(\mathrm{N}=185)$ & 56.1 & 56.2 & 58.6 & 57.3 \\
\hline Standard Deviation & 88.4 & 88.4 & 90.0 & 89.0 \\
\hline Cheap talk $(\mathrm{N}=157)$ & 30.5 & 30.3 & $36.1^{* * *}$ & 35.5 \\
\hline Standard Deviation & 52.9 & 51.9 & 55.3 & 54.5 \\
\hline Petition $(\mathrm{N}=222)$ & 34.5 & $35.3^{* *}$ & $38.0^{* * * *}$ & 38.2 \\
\hline Standard Deviation & 51.0 & 50.9 & 51.3 & 51.0 \\
\hline \multicolumn{5}{|c|}{ By scenario and experimental treatment } \\
\hline \multicolumn{5}{|c|}{ Drug } \\
\hline Baseline $(N=41)$ & 31.1 & 29.5 & 33.9 & 30.2 \\
\hline Cheap talk $(\mathrm{N}=55)$ & 20.9 & 20.7 & $25.2^{* * * *}$ & 24.7 \\
\hline Petition $(\mathrm{N}=97)$ & 15.6 & 15.3 & 16.6 & 16.6 \\
\hline \multicolumn{5}{|l|}{ Move } \\
\hline Baseline $(\mathrm{N}=83)$ & 92.5 & 93.6 & 95.5 & 94.7 \\
\hline Cheap talk $(\mathrm{N}=42)$ & 63.3 & 65.5 & $77.5^{* *}$ & 76.8 \\
\hline Petition $(N=63)$ & 65.2 & $67.1^{*}$ & $72.8^{* * *}$ & 72.6 \\
\hline \multicolumn{5}{|l|}{ Regulation } \\
\hline Baseline $(\mathrm{N}=61)$ & 23.5 & 23.2 & $25.0^{* * *}$ & 24.7 \\
\hline Cheap talk $(N=60)$ & 16.2 & 14.5 & $17.1^{*}$ & 16.5 \\
\hline Petition $(\mathrm{N}=62)$ & 33.1 & $34.1^{* *}$ & $36.0^{* *}$ & $36.8^{* * *}$ \\
\hline
\end{tabular}

Bold characters for a given round indicate a mean WTP differing from baseline WTP with $\mathrm{p}<.05$. Asterisks indicate a mean WTP differing significantly from the preceding round for a given scenario/treatment: ${ }^{*}$ if $p$-value $<.1$, ** if $p$-value $<.05, * * *$ if $p$-value.<. 01

on social cues. Surprisingly, however, participants who decrease their WTP in the cheap talk treatment are likely to already have a lower WTP than the mean.

Finally, we examine the impact of the participants' self-assessed prior knowledge of air pollution on the propensity to revise in rounds 2 and/or 4 (after social cues are provided) and in round 3 (i.e. after scientific information is provided). Prior knowledge means that respondents assessed their self-reported knowledge of air pollution as "good" or "very good", whereas no prior knowledge means they assessed it as "very bad", "bad" or "average". We find prior knowledge to have more impact on the probability of revision, either upwards or downwards, after social cues $(p=.094)$ but less impact on revision after scientific information delivery ( $p=.0397)$. This can be interpreted as showing that better informed participants are less likely to revise when additional information is of a scientific nature, but slightly more likely when information is based on others' beliefs (through displayed mean WTP in rounds 2 and/ or 4).

\subsection{Magnitude of the effect of information provision on WTP}

Table 3 presents the magnitude of the effect of social cues and scientific information on mean WTP, by experimental treatment and scenario. First, over the whole sample, social cues have no significant effect on WTP values. However, scientific information provision has a significant and positive effect: on average subjects revise their WTP upwards by $8.3 \%$ (paired $t$-test, $p<.0001$ ). Second, when mean WTP is computed by experimental treatment, we observe a decrease in WTP values w.r.t. baseline for all rounds, in both the cheap talk and the petition treatments (mean difference tests by round with p-values always lower than .006). Apparently, asking respondents to think about over- or under-stating a WTP value, i.e. a neutral cheap talk script, has a general downward effect on WTP in our setting. ${ }^{7}$ We observe that social cues have a significant and positive effect only in round 2 for the petition treatment (paired $t$-test, $p=.035$ ). Scientific information leads to an increase in mean WTP, significant in the cheap talk and petition treatments $(p<.001)$ but not in the baseline treatment $(p=.137)$. The combined social and scientific cues partly mitigate the downward effect on average WTP in these treatments using specific devices (cheap talk and a commitment device) intended to make respondents take their valuation task more seriously.

Third, the effect of treatments on WTP values depends on the scenario implemented, as shown at the bottom of Table 3 where the data are broken down by scenario. In the drug scenario, the sole significant change found across rounds is an increase following scientific information provision in the cheap talk treatment $(p<.001)$. In the move scenario, the scientific information effect is found both with cheap talk $(p=.012)$ and with the petition $(p=.0001)$; when combined with the petition, social cues also lead to a significant increase in round $2(p=.072)$. In the regulation scenario, scientific information has a significant and positive effect in all treatments ( $p=0.006$ for baseline, $p=0.079$ for cheap talk and $p=0.021$ for petition); when combined with the petition, social cues also have a significant effect in rounds $2(p=0.023)$ and $4(p=0.024)$. It is also interesting to note that average WTPs for the four rounds of the regulation scenario are higher than for the two other scenarios in the petition treatment, whereas average WTPs are

\footnotetext{
${ }^{7}$ See Ami et al. (2011) for a detailed analysis of the effect of cheap talk in our setting.
} 
lower in the two other treatments. This can be explained by the fact that the drug and move scenarios do not involve any political commitment to protect the environment, whereas the regulation scenario involves nationwide environmental conservation. Only the latter is in line with the proposition presented to respondents in the petition (Ami et al., 2014). In social psychology terms, the similarity of the two consecutive requests in the regulation scenario (first signing the petition, second stating a WTP) increases compliance with the second request (Joule and Beauvois, 1998), leading to higher WTP. Conversely, the petition in the drug and move scenarios has a negative effect on WTP because no environmental conservation is involved.

Fourth, the same results interpreted by treatment indicate that social cues have no effect in the baseline and cheap talk treatments, and that scientific information provision significantly increases WTP under the regulation scenario in the baseline treatment, and under all three scenarios in the cheap talk treatment. In the petition treatment, social cues have no significant effect under the drug scenario, but a significant effect in round 2 under the move scenario and in rounds 2 and 4 under the regulation scenario. In the latter design, all the dimensions of the valuation exercise tend towards a public decision framework, which may explain why respondents are more sensitive to the WTP values of other participants. Scientific information provision induces significant increases in WTP under the move and regulation scenarios in the petition treatment.

\section{Econometric analysis}

So far, however, we have considered only differences in mean WTP and have not accounted for potential composition effects across sessions. We therefore need to confirm the above findings on the effects of cheap talk, the commitment device, social cues and scientific information provision in a more systematic way, taking into account respondents' heterogeneity. We do so by considering the following econometric model that consists of four equations:

$$
\begin{aligned}
& W T P_{i, 1}=\alpha_{i}+\varepsilon_{i} \\
& W T P_{i, 2}=W T P_{i, 1}+\gamma_{1} S C 1_{i} \\
& W T P_{i, 3}=W T P_{i, 2}+\delta \\
& W T P_{i, 4}=W T P_{i, 3}+\gamma_{2} S C 2_{i}
\end{aligned}
$$

where $\alpha_{i}$ is a respondent-specific effect that accounts for heterogeneity of preferences, $S C 1$ and $S C 2$ are the mean session WTP displayed in round 1 and 3 respectively and $\varepsilon_{i}$ an idiosyncratic error term. In this model, participants combine their prior $W T P, W T P_{i, 1}$, with the social cues and scientific information at each round of the procedure. The parameters $\gamma_{1}, \gamma_{2}$ and $\delta$ stand for the influence of SC1 nor SC2 and scientific information respectively. The model is reminiscent of the anchoring/starting point bias models in the stated preference literature on double-bounded elicitation mechanisms. In these models, the respondent combines his/her prior WTP value with the first bid value - irrelevant to the value of the good but used as a cognitive anchor - to respond to the second bid (see, e.g., Herriges and Shogren, 1996; Aprahamian et al., 2007). The main difference in our setting is that information provision may play a role in forming preferences. Like anchoring and starting point bias models, the model that consists of equations (2)-(5) can be rewritten using a simple panel data regression (see, e.g., Whitehead, 2002; for an application to the anchoring/shift model) such that:

$$
W T P_{i, t}=\alpha_{i}+\gamma_{1}\left(r_{2}+r_{3}+r_{4}\right) S C 1_{i}+\delta\left(r_{3}+r_{4}\right)+\gamma_{2}\left(r_{4}\right) S C 2_{i}+u_{i, t}
$$

where $t=1, \ldots, 4$ indexes the round, $r_{2}, r_{3}, r_{4}$ are dummy variables specific to each round of the elicitation procedure that take the value 1 and zero otherwise. Since, as seen in section 3.1, respondents whose WTP is below the mean tend to revise upwards whereas respondents above the mean revise downwards, the model calls for some flexibility. Otherwise, it might spuriously be concluded that social cues and/or scientific information have no impact on WTP because the two effects cancel out on average. Thus, we differentiate between the two effects by considering that parameters $\gamma_{1}, \gamma_{2}$ and $\delta$ depend on which side of the mean WTP a respondent's elicited WTP falls. This means considering six parameters instead of three: $\left(\gamma_{1 b}, \gamma_{1 a}, \gamma_{2 b}, \gamma_{2 a}, \delta_{b}, \delta_{a}\right)$, where subscript $b$ stands for WTP values below the mean and subscript $a$ stands for WTP above the mean. For the social cues, we consider the mean WTP computed from the previous round, which were displayed to respondents. For scientific information provision, we consider the mean WTP displayed in round 1 , since mean WTP from round 2 was not displayed.

In practice, we estimate three models, one for each treatment: baseline, cheap talk and petition. In anchoring models, the fact that subsequent WTP values are combinations of previous WTP values and the bid proposed during the elicitation procedure can introduce heteroscedasticity (see Aprahamian et al., 2007). This is problematic, insofar as anchoring models are based on dichotomous dependent variables and heteroscedasticity potentially induces inconsistency of model parameters (Yatchew and Griliches, 1985) in addition to inefficiency. In our case, we observe continuous WTP values and the estimated parameters are unbiased and consistent in the presence of heteroscedasticity, although the estimated variance-covariance matrix is not correct. ${ }^{8}$ It is therefore important to use a robust estimate of the variance-covariance matrix that controls for heteroscedasticity to make correct statistical inference.

In Table 4, we present the estimated parameters together with their associated p-values for the three treatments. For the sake of simplicity, we consider WTP values in logarithms to avoid censoring issues. Variables $\left\{a_{i}^{t, s}\right\}$ are dummy variables that take value 1 if $W T P_{i, t}<\overline{W T P_{i, s}}$ and zero otherwise. As our focus is on the causes of WTP revision within a respondent, we estimate fixed effects

\footnotetext{
${ }^{8}$ This is also why it is important to consider the impact of information on the scale parameter in discrete choice experiment (DCE) models (see Czajkowski et al., 2015, 2016; for a detailed analysis of this issue).
} 
Table 4

Fixed-effect panel data estimations.

\begin{tabular}{|c|c|c|c|c|c|c|c|}
\hline \multirow[t]{2}{*}{ Variables } & \multirow[t]{2}{*}{ Parameters } & \multicolumn{2}{|l|}{ Baseline } & \multicolumn{2}{|l|}{ Cheap talk } & \multicolumn{2}{|l|}{ Petition } \\
\hline & & Parameter & $p$-value & Parameter & $p$-value & Parameter & $p$-value \\
\hline Average individual specific effect & $\alpha$ & 3.2793 & 0.000 & 2.7724 & 0.000 & 2.9051 & 0.000 \\
\hline$\left(r_{2}+r_{3}+r_{4}\right) \times a_{i}^{1,1} \times S C 1_{i}$ & $\gamma_{1 b}$ & 0.0004 & 0.436 & 0.0027 & 0.001 & 0.0022 & 0.000 \\
\hline$\left(r_{2}+r_{3}+r_{4}\right) \times\left(1-a_{i}^{1,1}\right) \times S C 1_{i}$ & $\gamma_{1 a}$ & -0.0003 & 0.612 & -0.0015 & 0.292 & -0.0003 & 0.702 \\
\hline$\left(r_{3}+r_{4}\right) \times a_{i}^{2,1}$ & $\delta_{b}$ & 0.1265 & 0.000 & 0.2099 & 0.000 & 0.1457 & 0.000 \\
\hline$\left(r_{3}+r_{4}\right) \times\left(1-a_{i}^{2,1}\right)$ & $\delta_{a}$ & -0.0447 & 0.294 & 0.0538 & 0.274 & 0.0255 & 0.456 \\
\hline$\left(r_{4}\right) \times a_{i}^{3,3} \times S C 2_{i}$ & $\gamma_{2 b}$ & -0.0003 & 0.467 & 0.0000 & 0.996 & 0.0008 & 0.083 \\
\hline$\left(r_{4}\right) \times\left(1-a_{i}^{3,3}\right) \times S C 2_{i}$ & $\gamma_{2 a}$ & 0.0004 & 0.487 & 0.0020 & 0.076 & 0.0003 & 0.687 \\
\hline Within $R^{2}$ & & \multicolumn{2}{|l|}{0.072} & \multicolumn{2}{|l|}{0.233} & \multicolumn{2}{|l|}{0.180} \\
\hline Between $R^{2}$ & & \multicolumn{2}{|l|}{0.494} & \multicolumn{2}{|l|}{0.135} & \multicolumn{2}{|l|}{0.128} \\
\hline Overall $R^{2}$ & & \multicolumn{2}{|c|}{0.177} & \multicolumn{2}{|c|}{0.013} & \multicolumn{2}{|c|}{0.025} \\
\hline F-test & & \multicolumn{2}{|c|}{$6.81(p$-value $<.01)$} & \multicolumn{2}{|c|}{$22.47(p$-value $<.01)$} & \multicolumn{2}{|c|}{$23.56(p$-value $<.01)$} \\
\hline
\end{tabular}

models that control for all time-invariant differences between individuals (including scenario effects or knowledge). ${ }^{9}$ Our results are two-fold. First, we find that scientific information has a strong significant influence, but only on participants whose WTP is below the mean WTP displayed in round 2 of the procedure. The results hold for all three treatments. Second, social cues have a mixed effect on elicited WTP. In the baseline treatment, we observe no direct effect on WTP values from displaying mean WTP, neither with SC1 nor SC2. In the cheap talk treatment, only respondents with WTP below the mean prior WTP elicited in round 1 and above the mean WTP elicited in round 3 respond to social cues, by revising their WTP value upwards. We also observe a positive $\gamma_{2 a}$, albeit only significant at a $10 \%$ level, in the cheap talk treatment. This indicates that respondents above the mean revise their WTP upwards after SC2. This result is difficult to interpret. One possible explanation, however, could be that participants over-devalue their WTP under cheap talk when they are not familiar with the good. When they receive extrinsic cues, in the form of scientific information or social cues, they correct this over-correction by revising their WTP upwards. This would mean that caution should be used when implementing a cheap talk script where goods are not familiar. Cheap talk may well correct a lack of information rather than hypothetical bias. In the petition treatment, the mean WTP has the same effect as in the cheap talk treatment: respondents with WTP below the mean revise upwards. However, the mean WTP displayed in round 4 now induces respondents below the mean, and not above it, to revise their WTP upwards. As seen in section 3.2, the cheap talk and petition treatments seem to make respondents more sensitive to the scientific information, encouraging them to take the valuation exercise seriously.

\section{Discussion and concluding remarks}

Stated preference surveys involve creating markets for non-market goods that are often unfamiliar to respondents or for which scientific information is lacking or controversial. With non-market goods, however, unlike experience goods in markets, survey respondents do not acquire experience through consumption events but rather during the survey itself. Consequently, information provision is a key aspect of stated preference survey design. Stated preference research has essentially focused on providing objective information about the good, the payment mechanism, the cost, etc. Only a few authors have explored how the opinions of others can influence elicited WTP values and, to our knowledge, no authors have addressed the combined effect of both types of information in a comprehensive way. In our CV experiment, we apply an original within-subjects procedure that introduces both objective information and social cues gradually in a large-group experimental setting. We are therefore able to assess how respondents react to different types of information and how such information may interact with other survey devices: cheap talk and commitment obtained in the guise of signing a petition.

Our descriptive statistics results are two-fold. First, we find that social cues have little direct effect on WTP values. Only a small proportion of respondents revise their WTP values after information about the mean WTP of the whole group is displayed. This is true for both social cues and for all treatments considered. When respondents revise after a social cue, those whose WTP is below the mean tend to revise upwards, while those above the mean tend to revise downwards. More detailed statistics on the joint distribution of the revisions at the different steps of the procedure indicate that most of the respondents who revise after SC1 only revise at this step of the procedure. At the aggregate level, the magnitude of the WTP revision induced by social cues does not lead to a significant change: mean and variation of the WTP distribution remain unaffected. Second, in our setting, scientific information has a significant positive effect on elicited WTP values. More than one third of the participants respond to scientific information, with $30 \%$ of them revising upwards. Those who revise upwards tend to have lower WTP values than the mean WTP. Moreover, revision in response to scientific information is likely to be the only WTP revision. The effect of scientific information is strong, and this holds whatever the treatment

\footnotetext{
${ }^{9}$ We tested whether a fixed or random effects model was appropriate, using Hausman tests. For each scenario, Hausman tests strongly reject the null of no correlation between the unobserved individual effect and the covariates matrix ( $p<0.001$ in all three scenarios). This means that parameter estimates in the fixed effects model are consistent, whereas parameter estimates in the random effects model are not consistent.
} 
considered.

These descriptive results lead us to conduct a structural econometric analysis of our procedure. We incorporate the influence of social cues and scientific information in an anchoring-like model that considers that respondents combine their WTP elicited in the previous step of the procedure with the new information. Moreover, we introduce different influence parameters depending on which side of the mean respondents' WTP falls, below or above. We show that the model is parsimonious enough to be estimated by a simple fixed effects panel data regression allowing us to control both observed and unobserved heterogeneity. Structural results confirm that social cues have little or no direct effect on WTP values, while scientific information has a clear direct positive effect on WTP values.

What emerges clearly from the data is that the effect of both social clues and scientific information on WTP values depends strongly on which side of the mean respondents' WTP falls. Social cues have no direct effects on WTP values in the baseline, but only respondents whose WTP is below the mean displayed in round 1 revise upwards as a result of scientific information ${ }^{10}$. In the cheap talk treatment, participants with WTP below the mean revise upwards after the mean WTP is displayed in round 2, while it is those with WTP above the mean who revise upwards in round 4 (although the parameter is not very significant). Again, only respondents below the mean tend to revise their WTP value after receiving scientific information. In the petition treatment, the effect of social cues and scientific information is also dependent on whether respondents' WTP falls on one or the other side of the mean WTP. Scientific information induces a revision upwards for those below the mean and both social cues induce a revision upwards for those below the mean (as in the cheap talk treatment, the parameter associated with the revision after SC2 is not very significant). One interpretation of the mixed effect of social cues is that in both the cheap talk and the petition treatments, and unlike the baseline, others are explicitly involved in the survey design - whether directly in the cheap talk script ("previous studies have shown that participants in stated preference surveys ...”) or indirectly in the petition treatment through social norms (i.e. environmental preservation). This may well trigger the direct effect of social cues on WTP values: the cheap talk or the petition intended here as a commitment device are, at least partly, social cues as well.

Our descriptive results, together with the econometric results, shed new light on the interacted effect of social cues and objective information. First, we observe that scientific information per se induces respondents who fall below the social cue WTP value to revise their WTP upwards. Second, descriptive statistics on the joint revision of WTP tell us that those who revise after receiving scientific information only revise in round 3. Social cues therefore provide a reference point for scientific information to operate. Does this mean that providing scientific information is not effective without social cues? The answer is obviously no. As mentioned previously, many authors have shown that providing objective information has a significant effect on elicited WTP.

What emerges from our work is that respondents in stated preference survey may well think in relative terms with regard to others' value judgment, and this can affect how objective information is processed. The fact that only those whose WTP is below the mean respond to scientific information even suggests that these respondents need an objective and credible source of information to react to what others think. This should not come as a surprise: social psychology demonstrated long ago that people are sensitive to what others think and do (see, e.g., the seminal experiments of Sherif, 1936; and Asch, 1955). In particular, informational social influence can be particularly strong when a situation is ambiguous or uncertain (Cialdini and Goldstein, 2004). This is often the case with unfamiliar goods, even when researchers attempt to define clear hypothetical valuation tasks (through scenario design, elicitation techniques, cheap talk scripts, etc.).

We suggest that the construction and the provision of social cues should be added to the list of tools and controls for stated preference methods. The general idea would be for stated preference surveys to mimic how consumers acquire information in real markets. Respondents would be provided with extrinsic cues from experts and other respondents, possibly on demand. Our sequential procedure would be a good starting point, but it would need to be more realistic. The literature on experience goods in marketing research could be helpful in that respect. At the very least, some questions about the implicit social cues respondents may be using should be added to the questionnaire.

This of course implies that further research is needed. For instance, in our experiment, we used mean WTP values as social cues because means and averages are usually well understood by the public. But it would be very interesting to assess if and how other statistics on WTP distribution influence elicited WTP values, and how respondents subsequently process objective information. Other investigations could examine the link between prior knowledge, self-reported uncertainty and social cues. ${ }^{11}$ Thus, the next step might be to explore the connection between how social cues are constructed and displayed to respondents and their prior knowledge/selfreported uncertainty. We believe that the research program on the Bayesian truth serum put forward in Prelec (2004) and Prelec et al. (2017) holds promise in that respect. ${ }^{12}$ Stepping back into the lab could be the most effective way to go for future research, and could give rise to interdisciplinary investigations reaching beyond stated preference survey.

\footnotetext{
${ }^{10}$ Note that using the displayed mean WTP in round 1 or the undisplayed mean in round 2 leads to the same conclusion, as there is no significant difference in mean WTP between these two rounds.

${ }^{11}$ We think that our structural econometrics is a good starting point for this. The main difficulty that we see lies in considering prior knowledge and self-reported uncertainty as purely exogenous variables that can be introduced directly into influence parameters. The exploration of the relationship between these measures and sensitivity to social cues and objective information may well require more structural work, possibly along the lines of Czajkowski et al. (2016) in DCE surveys.

${ }^{12}$ In particular, Prelec and colleagues show that for aggregating value judgments with no objective answer (such as preferences regarding nonmarket goods), the point of view of the minority is a key ingredient. Their algorithm for aggregating judgments identifies non conformists with respect to the majority view (thus implicating the way social cues are defined) and uses the degree of certainty of their judgments compared to that of the majority view (thus implicating prior knowledge and self-reported certainty).
} 


\section{Acknowledgments}

This research was carried out thanks to the support of the $A^{*}$ MIDEX grant AMSE (ANR-11-IDEX-0 001-02) funded by the "Investissements d'Avenir" French Government program, of French Research Ministry grant (no. 045666 ACI Santé et Environment), of GREEN-Econ (ANR-16-CE03-0005) managed by the French National Research Agency and the technical and financial support from the Provence-Alpes-Côte-d'Azur (PACA) Regional Council. We thank the three anonymous reviewers for helping us improve the paper and Marjorie Sweetko for her thorough re-reading of the English. We are also grateful to all the respondents that answered our questionnaires, the PACA regional Council and to the team members, especially Pierre-Henri Bono, for assistance during the experiment.

\section{Glossary}

CV Contingent Valuation

DCE Discrete Choice Experiment

USD United States Dollar

WTP Willingness-To-Pay

\section{Appendix H. Supplementary data}

Supplementary data to this article can be found online at https://doi.org/10.1016/j.jocm.2018.09.001.

\section{Appendix A. Sample characteristics}

Table 5

Whole Sample characteristics

\begin{tabular}{|c|c|c|c|c|c|}
\hline \multirow[t]{2}{*}{ Variable } & \multirow[t]{2}{*}{ Description } & \multicolumn{4}{|c|}{ Whole sample } \\
\hline & & Mean & (sd) & $\operatorname{Max}$ & $\min$ \\
\hline Male & Subject is male $(=1)$ & .345 & $(.47)$ & 1 & 0 \\
\hline Age & Age of the subject (years) & 38.76 & $(14.05)$ & 85 & 19 \\
\hline NPers & Number of persons in the household & 2.53 & $(1.27)$ & 8 & 1 \\
\hline Income & Monthly individual income (euros) & 1272 & (995) & 6300 & 0 \\
\hline PrivHealthIns & Subject has private health insurance $(=1)$ & .806 & $(.39)$ & 1 & 0 \\
\hline LiveMars & Subject lives in Marseilles $(=1)$ & .769 & $(.42)$ & 1 & 0 \\
\hline Owner & Status of the occupant of the place of residence $(=1)$ & .457 & $(.49)$ & 1 & 0 \\
\hline Smoker & Subject is a smoker $(=1)$ & .127 & $(.33)$ & 1 & 0 \\
\hline
\end{tabular}

Table 6

Sample characteristics by treatment condition and Two-sample test for mean equality**

\begin{tabular}{|c|c|c|c|c|c|c|c|c|c|c|}
\hline \multirow[t]{3}{*}{ Variable } & \multirow[t]{3}{*}{ Description } & \multicolumn{3}{|c|}{ Baseline } & \multicolumn{3}{|c|}{ Cheap Talk } & \multicolumn{3}{|c|}{ Petition } \\
\hline & & \multicolumn{3}{|c|}{$\mathrm{n}=185$} & \multicolumn{3}{|c|}{$\mathrm{n}=157$} & \multicolumn{3}{|c|}{$\mathrm{n}=222$} \\
\hline & & Mean & (sd) & $\begin{array}{l}p- \\
\text { value* }^{*}\end{array}$ & Mean & (sd) & $\begin{array}{l}p- \\
\text { value }^{*}\end{array}$ & Mean & $(\mathrm{sd})$ & $\begin{array}{l}p- \\
\text { value* }^{*}\end{array}$ \\
\hline Male & Subject is male $(=1)$ & .362 & $(.035)$ & .794 & .350 & $(.038)$ & .894 & .351 & $(.032)$ & .896 \\
\hline Age & Age of the subject (years) & 39 & $(1.02)$ & .681 & 39 & $(1.15)$ & .489 & 38 & $(.92)$ & .294 \\
\hline NPers & Number of persons in the household & 2.6 & $(.09)$ & .040 & 2.3 & $(.09)$ & .044 & 2.5 & $(.09)$ & .817 \\
\hline Income & Monthly individual income (euros) & 1303 & $(72)$ & .597 & 1192 & $(64)$ & .175 & 1303 & $(68)$ & .552 \\
\hline PrivHealthIns & Subject has private health insurance $(=1)$ & .837 & $(.027)$ & .177 & .789 & $(.032)$ & .536 & .792 & $(.027)$ & .504 \\
\hline LiveMars & Subject lives in Marseilles $(=1)$ & .745 & $(.032)$ & .363 & .770 & $(.033)$ & .966 & .788 & $(.027)$ & .389 \\
\hline Owner & $\begin{array}{l}\text { Status of the occupant of the place of } \\
\text { residence }(=1)\end{array}$ & .448 & $(.036)$ & .770 & .477 & $(.039)$ & .550 & .450 & $(.033)$ & .788 \\
\hline Smoker & Subject is a smoker $(=1)$ & .135 & $(.025)$ & .714 & .114 & $(.025)$ & .555 & .130 & $(.022)$ & .865 \\
\hline
\end{tabular}

Bold characters when p-value $<.05$.

*P-values for mean equality tests between the sample exposed to a specific treatment and the remaining sample.

$* *$ Two-sample test for unpaired samples and unequal variances. 


\section{Appendix B. Drug scenario}

You are going to be the main actor in our scenario. You will have to take the best decision for yourself and your household. Let's imagine that the Ministry of Health has authorized a new drug, different from those currently available. It allows the long-term effects of air pollution exposure to be reduced by half. It simply involves taking a pill every month, which, by the combined action of several vitamins, stimulates immunological responses. It has no side effects and no contra-indications. It can be taken by any person who is more than 5 years old.

This new drug is reimbursed neither by the social security system nor by the CMU (state means-tested health cover) nor by the complementary health insurance policies. This implies that, if you choose to buy it, you will bear the full cost. We would like to know how much you would be willing to pay to use this drug, which would reduce by half the long-term diseases and mortality risks associated with air pollution. Do not forget that this money will be drawn from your household's budget! You will therefore have less money at the end of the month for consumption or savings.

\section{Appendix C. Move scenario}

You are going to be the main actor in our scenario. You will have to take the best decision for yourself and your household. Let's imagine that you and your household have to move. You can choose between two cities which are exactly equivalent in terms of inhabitants, working conditions, schools, climate, public services, cultural life, transport, housing, surroundings, etc. There is only one difference between them: the level of atmospheric pollution. The first city - let's call it POL - is as polluted as Marseilles. And the second city - let's call it LESSPOL - is half as polluted as Marseilles.

The problem is that the cost of living is higher in LESSPOL (the less polluted city): housing, local taxes, public transport, etc. are more expensive. This means that if you choose to move to LESSPOL, you will have to pay more to have the same standard of living as in POL. We would like to know how much you would be willing to pay per month for you and your household to move to LESSPOL (the less polluted city) rather than to POL (the town as polluted as Marseilles). Do not forget that this money will be drawn from your household's budget! You will therefore have less money at the end of the month for consumption and savings.

\section{Appendix D. Regulation scenario}

You are going to be the main actor in our scenario. You will have to take the best decision for yourself and your household.

Let's imagine that new laws and rules are to be adopted to limit air pollution. Therefore industries, manufacturers of consumer products, public or private transport, will have to adopt less polluting technologies. Studies have shown that these new laws and rules will make it possible to reduce by half the number of highly polluted days in the PACA region, and particularly in Marseilles.

The implementation of these new technologies will induce higher costs in every-day life: energy, food and other goods, transport. This means that you will have to pay more to enjoy the same standard of living as before the implementation of these new laws and rules.

We would like to know how much you would be willing to pay per month for these new laws and rules to be implemented. Do not forget that this money will be drawn from your household's budget! You will therefore have less money at the end of the month for consumption and savings.

\section{Appendix E. Scientific information}

Actually, few people realize the impact of air pollution. There are three different types of effects: irritant effects (that lead to additional illnesses), fatal effects (that lead to additional premature deaths) and effects on the living environment. Exposure to high levels of air pollution over several years leads to a deterioration in health status. Researchers and doctors have noticed for about 30 years that when air pollution levels peak, and in locations where air pollution levels are high, more illness and more deaths are observed. When we study the links between air pollution and health, one issue is to determine whether the visit to a doctor or the hospital stay of a given individual is caused by air pollution. Complex studies have therefore been done worldwide on large samples of individuals, and researchers have been able to compute the number of cases that, on average, were due to air-pollution exposure. The additional illnesses due to irritant effects cause health problems: irritated eyes (red, watering and smarting eyes), headaches, sore throats, coughing fits, flu symptoms (with fever and tiredness), asthma attacks and even hospitalizations for pneumonia, acute asthma or respiratory and heart conditions.

Move scenario: The people who live in PEUPOL face a less polluted environment and therefore have less health problems. It can be computed that, during the next 20 years, 100 people living in LESSPOL rather that POL ...

Regulation scenario: It can be computed that, due to the implementation of new rules and laws applied to polluting firms and activities during the next 20 years, a group of 100 people ...

Drug scenario: It can be computed that, during the next 20 years, a group of 100 people that chooses to take the Drug ...

... will have 20 less asthma attacks, 14 less visits to general practitioners, 500 less working days off for tiredness, irritated eyes or respiratory diseases, and ONE less 10-day hospitalization for heart conditions. The additional deaths There are many causes of death and they vary according to age: young people die more in transport accidents, old people die more due to cardiovascular 
diseases. If you take 100 people randomly in France, 41 will die before 80 . The three major causes of death are: cancers (18 deaths), cardiovascular diseases (14 deaths) and all accidental causes (4 deaths).

Air-pollution deaths should be added to the list. Researchers have found that deaths are more numerous and occur in younger people in polluted areas than in less polluted areas.

Move scenario: Hence, if you take 100 people living in LESSPOL, ...

Regulation scenario: Hence, if the regulation is implemented, among 100 people, ...

Drug scenario: Hence, if you take 100 taking the drug, ...

... ONE will die before 80 because of his/her poor health related to low air quality. This person will have lost around 10 years of life.

Move scenario: If these 100 people live in POL, ...

Regulation scenario: If the regulation are not implemented, ...

Drug scenario: If these 100 people don?t take the drug, ...

... TWO of them will die. We can hence say that 1 person per 100 can live 10 years more

Move scenario: ... by living in LESSPOL rather than in POL.

Regulation scenario: ... if the regulation is implemented.

Drug scenario: ... by taking the drug.

The effects on the living environment cause effects that are not related to health. They make buildings dirty, so that they need to be cleaned more frequently, they smell bad and create a cloud of brown dust and particulates. You are now better informed about the effects of air pollution.

\section{Appendix F. Cheap talk script}

Similar studies show that the amount respondents are willing to pay can differ from what they would pay in real life.

For instance, some respondents state a lower willingness to pay in relation to what they would otherwise pay, or even refuse to pay anything. This could be explained by the fact that they want to express a point of view such as "I have the right to breathe good quality air" or "I shouldn't have to pay for good quality air; it's polluting firms or the state who should pay".

On the other hand, people may state a higher amount than they would pay in real life, that is, if they really had to pay out of their pockets. We would like you to try not to behave like these people, but to answer as sincerely as possible. If you want to make any comments concerning the amount of money you state which you didn't have the opportunity to verbalize during the procedure, don't hesitate to write them down at the end of the questionnaire, where a space is devoted to your comments.

\section{Appendix G. Petition script}

Soon, all the candidates for the next presidential election will be known. You may know that for several days, since a few days, a petition has been circulating in France. The aim of this petition is to obtain a commitment from each candidate, whatever his/her political background, to include the questions of environmental conservation in his/er program, because it is important that each of us is able to make informed choices.

We need a lot of signatures. Therefore, if you think, like us, that issues of environmental conservation are essential issues on which candidates for the presidential election should take a clear stance, we invite you to sign this petition. Thank you.

\section{References}

Ajzen, I., 1996. The directive influence of attitudes on behavior. In: Gollwitzer, P., Bargh, J.A. (Eds.), Psychology of Action. Guilford, New York, NY, pp. 385-403. Alberini, A., Cropper, M., Krupnick, A., Simon, N., 2004. Does the value of a statistical life vary with age and health status? Evidence from the US and Canada. J. Environ. Econ. Manag. (48), 769-792.

Alvarez-Farizo, B., Hanley, N., Barberán, R., Lázaro A, A., 2007. Choice modeling at the "market stall": individual versus collective interest in environmental valuation. Ecol. Econ. 60, 743-751.

Ami, D., Aprahamian, F., Chanel, O., Luchini, S., 2011. A test of cheap talk in different hypothetical contexts: the case of air pollution. Environ. Resour. Econ. 50 (1), 111-130. Ami, D., Aprahamian, F., Chanel, O., Joulé, R.-V., Luchini, S., 2014. Willingness to pay of committed citizens: a field experiment. Ecol. Econ. 105, 31-39.

Andreoni, J., 1988. Why free ride? Strategies and learning in public good experiments. J. Publ. Econ. 37 (3), 291-304.

Aprahamian, F., Chanel, O., Luchini, S., 2007. Modeling starting point bias and unobserved heterogeneity in contingent valuation surveys: an application to air pollution. Am. J. Agric. Econ. 89 (2), 533-547.

Aqueveque, C., 2006. Extrinsic cues and perceived risk: the influence of consumption situation. J. Consum. Market. 23 (5), $237-247$.

Aqueveque, C., 2008. The effect of extrinsic cues on imported wine evaluations: an experimental approach. J. Food Prod. Market. 14 (3), $33-47$.

Asch, S.E., 1955. Opinions and social pressure". Sci. Am. 193 (5), 31-35.

Bergstrom, J.C., Stroll, J.R., Randall, A., 1990. The impact of information on environmental commodity valuation decisions. Am. J. Agric. Econ. 72 (3), 614-621.

Carlsson, F., 2010. Design of stated preference surveys: is there more to learn from behavioral economics? Environ. Resour. Econ. 46 (2), $167-177$. 
Chanel, O., Cleary, S., Luchini, S., 2006. Does public opinion influence willingness- to-pay? Evidence from the field. Appl. Econ. Lett. 13 (13), 821-824.

Chanel, O., Cleary, S., Luchini, S., 2007. Individual responsiveness to information in CV surveys: commitment matters. Rev. Écon. Polit. 117 (5), 761-779.

Chanel, O., Luchini, S., Massoni, S., Vergnaud, J.-C., 2011. Impact of information on intentions to vaccinate in a potential epidemic: swine-origin Influenza A (H1N1). Soc. Sci. Med. 72, 142-148.

Chetty, R., 2015. Behavioral economics and public policy: a pragmatic perspective. Am. Econ. Rev. 105 (5), 1-33.

Cialdini, R.B., Goldstein, N.J., 2004. Social influence: compliance and conformity. Annu. Rev. Psychol. 55, 591-621.

Cummings, R.G., Taylor, O., 1999. Unbiased value estimates for environmental goods: a cheap talk design for the contingent valuation method. Am. Econ. Rev. 89 (3), 649-666.

Czajkowski, M., Hanley, N., LaRiviere, J., 2015. The effects of experience on preferences: theory and empirics for environmental public goods. Am. J. Agric. Econ. 97 (1), 333-351.

Czajkowski, M., Hanley, N., LaRiviere, J., 2016. Controlling for the effects of information in a public goods discrete choice model. Environ. Resour. Econ. 63 (3), 523-544.

Desaigues, B., Rabl, A., Ami, D., Kene, B.M., Masson, S., Salomon, M.-A., Santoni, L., 2007. Monetary value of a life expectancy gain due to reduced air pollution: lessons from a contingent valuation. In: The Memorial Issue of REP for Brigitte Desaigues, Revue D'Economie Politique, vol. 5. pp. 675-698.

Fischhoff, B., 2005. Cognitive processes in stated preference methods. In: In: Mäler, K.-G., Vincent, J.R. (Eds.), Handbook of Environmental Economics, vol. 2 Elsevier B/V, Amsterdam Chap. 18.

Fleurbaey, M., Schokkaert, E., 2013. Behavioral welfare economics and redistribution. Am. Econ. J. Microecon. 5 (3), $180-205$.

Galbraith, J.K., 1971. A Contemporary Guide to Economics, Peace and Laughter". Houghton Mifflin, London.

Guria, J., Leung, J., Jones-Lee, M., Loomes, G., 2005. The willingness to accept value of statistical life relative to the willingness to pay value: evidence and policy implications, Environ. Resour. Econ. 32, 113-127.

Herriges, J., Shogren, J., 1996. Starting point bias in dichotomous choice valuation with follow-up questioning. J. Environ. Econ. Manag. 30 (1), $112-131$.

Jacquemet, N., James, A., Luchini, S., Shogren, J., 2011. Social psychology and environmental economics: a new look at ex ante corrections of biased preference evaluation. Environ. Resour. Econ. 48, 411-433.

Joulé, R.V., Beauvois, J.L., 1998. La Soumission Librement Consentie. Presses Universitaires de France, Paris.

Kiesler, C., 1971. The Psychology of Commitment. Experiments Linking Behavior to Belief. Academic Press, New York.

Krupnick, A., Alberini, A., Cropper, M., Simon, N., O'Brien, B., Goeree, R., Heintzelman, M., 2002. Age, health and the willingness to pay for mortality risk reductions: a contingent valuation study of Ontario residents. J. Risk Uncertain. 24, 161-186.

List, J., P. Sinha, Taylor, M., 2006. Using choice experiments to value non-market goods and services. Adv. Econ. Anal. Pol. 6 (2), 1-37.

Little, J., Berrens, R., 2004. Explaining disparities between actual and hypothetical stated values: further investigation using meta-analysis. Econ. Bull. 3 (6), 1-13.

Lohse, J., Goeschl, T., Diederich, J.H., 2017. Giving is a question of time: response times and contributions to an environmental public good. Environ. Resour. Econ. 67, 455-477. Maruyama, A., Kikuchi, M., 2004. Risk-Learning process in forming willingness- to-pay for egg safety. Agribusiness 20 (2), $167-179$.

Mitchell, R.C., Carson, R.T., 1989. Using Surveys to Value Public Goods: the Contingent Valuation Method. Resources for the Future, Washington D.C.

Munro, A., Hanley, N., 2001. Information, uncertainty and contingent valuation. In: Bateman, I., Willis, K. (Eds.), Valuing Environmental Preferences: Theory and Practice of the Contingent Valuation Method. Oxford University Press, Oxford, pp. 258-279.

Murphy, J.J., Allen, P.G., Stevens, T.H., 2005. A meta-analysis of hypothetical bias in stated preference valuation. Environ. Resour. Econ. 30 (3), 313-325.

Polomé, P., 2003. Experimental evidence on deliberate misrepresentation in referendum contingent valuation. J. Econ. Behav. Organisat. 52, 387-401.

Prelec, D., 2004. A Bayesian truth serum for subjective data. Science 306 (5695), 462-466.

Prelec, D., Seung, H.S., McCoy, J., 2017. A solution to the single-question crowd wisdom problem. Nature 541, $532-535$.

Robinson, L.A., Hammitt, J.K., 2011. Behavioral economics and regulatory analysis. Risk Anal. 31 (9), 1408-1422.

Rowe, R., D'Arge, R.C., Brookshire, D.S., 1980. An experiment on the economic value of visibility. J. Environ. Econ. Manag. 7 (1), 1-19.

Salazar, H.A., Oerlemans, L., 2016. Do we follow the leader or the masses? Antecedents of the willingness to pay extra for eco-products. J. Consum. Aff. 50 (2), 286-314.

Sherif, M., 1936. The Psychology of Social Norms. Harper, Oxford, England.

Shogren, J.F., Thunström, L., 2016. Do we need a new behavioral benchmark for BCA? J. Benefit-Cost Anal. 7 (1), $92-106$.

Spash, C.L., 2002. Informing and forming preferences in environmental valuation: coral reef biodiversity". J. Econ. Psychol. 23, 665-687.

Stefani, S., Scarpa R, R., Lombardi, G.V., 2014. An addendum to: a meta-analysis of hypothetical bias in stated preference valuation. Bio base Appl. Econ. 3, 175-184.

Viscusi, W., Magat, W.A., Forrest, A., 1988. Altruistic and private valuations of risk reduction. J. Pol. Anal. Manag. 7 (2), $227-245$.

Vossler, C.A., Doyon, M., Rondeau, D., 2012. Truth in consequentiality: theory ash and field evidence on discrete choice experiments. Am. Econ. J. Microecon. 4 (4), 145-171.

Whitehead, J.C., 2002. Incentive incompatibility and starting-point bias in iterative valuation questions. Land Econ. 78, $285-297$.

Yatchew, A., Griliches, Z., 1985. Specification error in probit models. Rev. Econ. Stat. 67, 134-139. 